Rudolf Jaworski

\title{
Die polnische Grenzminderheit in Deutschland 1920-1939
}

\section{Rahmenbedingungen und Ausgangspositionen der polnischen Grenzbevölkerung}

Die Entstehung der sogenannten Nachfolgestaaten nach dem Ersten Weltkrieg und die Neugestaltung der politischen Landkarte in Ostmitteleuropa waren mit Grenzziehungen verbunden, die aufgrund der komplizierten Siedlungsverhältnisse in diesem Raum fast nirgends eine völlige Deckungsgleichheit von Volks- und Staatsgrenzen zugelassen haben. Die Folge war u. a. die Abspaltung zahlreicher Grenzminderheiten, denen es aus verschieden Gründen verwehrt blieb, in den jeweils angrenzenden Staat, in dem ihre eigene Nationalität die Majorität der Bevölkerung gestellt hat, einbezogen zu werden und die statt dessen gezwungen waren, unter fremder Herrschaft „vor den Toren“" ihres Mutter- bzw. Vaterlandes auszuharren. Im Zeichen des damals allseits rigoros eingeklagten Rechts auf Selbstbestimmung der Völker waren damit von vornherein und langfristig komplizierte, weil strukturell vorgegebene Konfliktzonen geschaffen.

Das Deutsche Reich war mit seinen preußischen Ostprovinzen unmittelbar und gleich in zweifacher Weise in diese Vorgänge involviert, da es deutsche Bevölkerungsteile an den neu geschaffenen polnischen Staat hatte abgeben müssen und zugleich innerhalb der eigenen Staatsgrenzen noch polnische Restminderheiten verblieben waren. ${ }^{1} \mathrm{Mit}$ dem Zusammenbruch der Mittelmächte war zu Ende des Ersten Weltkrieges an der Ostgrenze des Deutschen Reiches eine unübersichtliche Situation entstanden. Deutsche Freiwilligenverbände im sogenannten „Heimat"- und „Grenzschutz Ost“ standen polnischen Volkswehren gegenüber. Deutsche und polnische Volksräte beanspruchten in gleicher Weise das Recht, als Ordnungsfaktoren respektiert zu werden. Der dezidierten Absicht der polnischen Verhandlungsführer in Versailles, die polnische Grenze unter Berufung auf ethnische Merkmale möglichst weit nach Westen vorzuschieben, stand der nicht minder entschlossene Wille deutscher Militärs und Provinzialregierungen entgegen, den Bestand der deutschen Ostprovinzen unter allen Umständen zu erhalten. Am frühesten trafen diese Gegensätze in der Provinz Posen aufeinander, die schon im Dezember 1918 fast vollständig unter polnische Kontrolle geraten war. Obwohl der territoriale Status quo, wenn man von der Provinz Posen einmal absieht, bis zum Beginn der Pariser Friedensverhandlungen behauptet werden konnte, hat diese dramatisch zugespitzte Übergangszeit entschieden zur Herausbildung einer antipolnischen Hysterie an der Ostgrenze beigetragen und auch in der Folgezeit eine übertriebene Alarmbereitschaft genährt.

\footnotetext{
1 Vgl. zu den folgenden Abschnitten Broszat, Martin: Zweihundert Jahre deutsche Polenpolitik. Frankfurt/M. 1975, S. 201 ff.; Riekhoff. Harald von: German-Polish Relations 1918-1933. Baltimore 1971, S. 13 ff. Schumacher, Rainer: Die preuBischen Ostprovinzen und die Politik des Deutschen Reiches 1918-1919. Diss. Köln 1985.
} 
Nach den Bestimmungen des Versailler Friedensvertrages hatte Deutschland erhebliche Gebietsabtretungen an den wiedererrichteten polnischen Staat zu leisten:2 Fast die gesamte Provinz Posen fiel an Polen, bei Deutschland verblieben lediglich $11 \%$ der damaligen Provinzfläche und $8 \%$ der Provinzbevölkerung, von Westpreußen waren Deutschland auch nur 23,3\% der Provinzfiäche und 19,4\% der Bevölkerung zuerkannt worden. Weniger gravierend waren die Einbußen in Schlesien und Ostpreußen ausgefallen. Hier waren darüber hinaus für umstrittene Territorien (südliches Ostpreußen und Oberschlesien) Abstimmungen vorgesehen, die im Falle Oberschlesiens Anhaltspunkte für eine Teilung dieser Region geben sollten und zu besonders heftigen, auch militärisch ausgetragenen Auseinandersetzungen geführt haben. Zusammen mit den vorausgegangenen deutsch-polnischen Konflikten unmittelbar nach Kriegsende - etwa in Verbindung mit dem Posener Aufstand - waren dies die einzigen bewaffneten Kämpfe, die Deutschland zur Sicherung seiner Grenzen ausgetragen hatte. Andere territoriale Einbußen, welche das geschlagene Deutschland im ElsaB oder an der Grenze zu Belgien und Dänemark hatte hinnehmen müssen, waren weniger dramatisch verlaufen. Sie sind auch längst nicht im selben AusmaB als Symbol der Niederlage und des Verlustes an imperialer Stellung empfunden worden, wie dies bei den Gebietsabtretungen an Polen der Fall gewesen ist.

Für diese divergierende Bewertung spielten sicherlich die unterschiedlichen Größenordnungen der im Westen und der im Osten erfolgten territorialen Beschneidungen eine wichtige Rolle. An der neuen Grenze zu Polen waren sie so umfangreich, daß die administrativen, wirtschaftlichen und militärischen Strukturen in den verbliebenen Ostgebieten teilweise völlig neu aufgebaut werden mußten. Aber nicht diese Aufgabe und die damit verbundenen Schwierigkeiten bildeten den eigentlichen Stein des Anstoßes, vermutlich auch nicht einmal so sehr die genaue Zahl der verlorengegangenen Quadratkilometer. Viel tiefer saß der Schock, daß an der Ostflanke des Reiches ein neuer Staat „von Frankreichs Gnaden“ auf territoriale Kosten des Deutschen Reiches entstanden war, mit Gebieten, die vor dem Kriege zum Rückgrat preußisch-deutscher Machtentfaltung gezählt hatten.

$\mathrm{DaB}$ ein „Saisonstaat" Polen mit offensichtlich geliehener Autorität der Westalliierten instand gesetzt worden war, sich ungestraft weite Teile der deutschen Ostmarken einzuverleiben, Ostpreußen zu bedrängen und Hoheitsrechte in Danzig wahrzunehmen, ist in Deutschland während der gesamten Zwischenkriegszeit als eine nationale Demütigung höchsten Grades empfunden worden. ${ }^{3}$ Bei einer solchen Sichtweise, die keinesfalls nur auf rechte und konservative Kreise beschränkt geblieben ist, war es nicht verwunderlich, daß die hartnäckige Forderung nach einer Revision der deutschen Ostgrenze zu den unverrückbaren Gravamina der deutschen Außenpolitik avancieren konnte und ein wesentliches Element im allgemeinen „Kampf gegen Versailles“ dargestellt hat.

\footnotetext{
$2 \mathrm{Vgl}$. auch zum Folgenden Baier, Roland: Der deutsche Osten als soziale Frage. Köln 1980, S. $149 \mathrm{ff}$.; Bohmann, Alfred: Menschen und Grenzen Bd. 1. Köln 1969. S. 187 ff.; Holzer. Jerzy: Das Ende des Ersten Weltkriege, Deutschlands Zusammenbruch und die erste Wiederherstellung des polnischen Staates. In: Nordost-Archiv NF II (1993) H. 1, S. 7-16; Krasuski, Jerzy: Stosunki polsko-niemieckie 1919-1932. Poznań 1975. S. 46 ff.

3 Siehe u.a. Fischer, Peter: Die deutsche Publizistik als Faktor der deutsch-polnischen Beziehungen 1919 1939. Wiesbaden 1991, insbesondere S. 11-17, 107-112; Kellermann. Volkmar: Schwarzer Adler - Weißer Adler. Die Polenpolitik der Weimarer Republik. Köln 1970, S. 32 ff.; Rexheuser, Rex: Deutsche Minderheit in Polen, polnische Minderheit in Deutschland 1920 bis 1939. In: Nordost-Archiv 20 (1987) H. 85, S. 10 f.; Riekhoff, S. 18-20, 383.
} 
Die anhaltende emotionale Aufladung der „blutenden Grenze“ zu Polen hat aber auch in negativer Weise auf die Behandlung der bei Deutschland verbliebenen polnischen Grenzminderheiten zurückgewirkt.

Was nach den Beschlüssen des Versailler Friedensvertrages sowie nach erbitterten Grenz- und Abstimmungskämpfen noch von den ehemaligen preußischen Ostprovinzen erhalten werden konnte, stellte zusammengenommen nurmehr einen bescheidenen, unzusammenhängenden und von sich aus kaum existenzfähigen territorialen Restbestand dar. Ostpreußen war durch die Errichtung des polnischen Korridors gänzlich vom Reichsgebiet abgeschnitten worden, von den Provinzen Posen und Westpreußen war nur ein Bruchteil übriggeblieben, der dann in einer neugeschaffenen Verwaltungseinheit Grenzmark Posen-Westpreußen zusammengefaßt bzw. Ostpreußen zugeschlagen worden ist. Der oberschlesische Teil der ehemaligen Provinz Schlesien war zuletzt nach Vorgaben der Siegermächte auf das Oppelner Gebiet zusammengeschrumpft. In all diesen Grenzgebieten gab es noch polnische Bevölkerungsgruppen, die teilweise in größerer Konzentration wie im südlichen Ostpreußen (Ermland und Masuren) oder in Westoberschlesien, dann wieder in weitgestreuter Aufsplitterung dies- und jenseits des polnischen Korridors weiterhin unter deutscher Staatshoheit verblieben waren und zusammengenommen die überwiegende Mehrheit der in Deutschland lebenden Polen ausgemacht haben. ${ }^{4}$

Zuverlässige Angaben zu den genauen Zahlenverhältnissen lassen sich indes nur schwer ermitteln. So schwanken beispielsweise die Schätzungen über die Gesamtzahl der in Deutschland lebenden Polen, einschließlich der polnischen Siedlungskolonien im Ruhrgebiet, in Berlin und in Mitteldeutschland für die Zwischenkriegszeit zwischen 800000 und 1,5 Millionen. ${ }^{5}$ Dabei darf nicht vergessen werden, daß die Nationalitätenstatistik für sich genommen über den Zweiten Weltkrieg hinaus lange Zeit selber Bestandteil deutsch-polnischer Auseinandersetzungen gewesen ist, daß außerdem die zeitgenössischen Erhebungskriterien bei den amtlichen Volkszählungen sehr vage gewesen sind, daß bestimmte Voten für oder gegen die polnische Volkszugehörigkeit von politischen Konjunkturen abhängig sein konnten und darum noch lange nichts über die tatsächlichen nationalen Verhältnisse an der deutsch-polnischen Grenze aussagten. Das gilt insbesonders für das deutsche amtliche Zahlenmaterial zu dem hier interessierenden Beobachtungszeitraum. Die gewollte Tendenz, die polnische Grenzminderheit statistisch verschwinden zu lassen bzw. auf ein Minimum zu reduzieren, kam allein dadurch zum Ausdruck, daß die polnischsprachige Bevölkerung durch die betonte Eigenwertigkeit des Masurischen und Oberschlesischen in kleine Sprachgruppen auseinanderdividiert worden ist. Wenn im folgenden dennoch auf die amtlichen Zählungen von 1925, 1933 und 1939 zurückgegriffen wird, so vor allem deswegen, weil durch sie für einen längeren Zeitabschnitt die grundlegenden Proportionen und Veränderungen polnischer Präsenz in den verbliebenen Ostprovinzen sichtbar gemacht werden kann und weil das Muttersprachenkriterium (rein polnisch, zweisprachig oder masurischer, oberschlesischer Dialekt) die spezifische Problematik dieser ethnischen Misch- und Übergangszonen sehr plastisch zum Ausdruck bringt. Der größeren Übersichtlichkeit wegen wurde der breiter

\footnotetext{
4 Dazu grundlegend Wrzesiniski. Wojciech: Polski ruch narodowy w Niemczech 1922-1939. Poznań 1970, S. $25 \mathrm{ff}$.

5 Vgl. beispielsweise die unterschiedlichen Berechnungen von Bohmann, S. 225-245; Wrzesiniski: Ruch Polski, S. 27-36.
} 
aufgefächerte zeitgenössische amtliche Fragenkatalog in die zwei Kategorien ,nur polnisch“ und ,zwei- oder regionalsprachig“ zusammengefaßt. Danach ergibt sich folgendes Zahlenbild: ${ }^{6}$

\begin{tabular}{|c|c|c|c|c|c|c|}
\hline & $\begin{array}{c}1 \\
\text { Mutte } \\
\text { nur } \\
\text { poln. }\end{array}$ & $\begin{array}{l}925 \\
\text { rsprache } \\
\text { zwei- oder } \\
\text { reg.sprach. }\end{array}$ & $\begin{array}{c}1 \\
\text { Mutte } \\
\text { nur } \\
\text { poln. }\end{array}$ & $\begin{array}{l}933 \\
\text { rsprache } \\
\text { zwei- oder } \\
\text { reg.sprach. }\end{array}$ & $\begin{array}{c}\text { Mutt } \\
\text { nur } \\
\text { poln. }\end{array}$ & $\begin{array}{l}1939 \\
\text { ersprache } \\
\text { zwei- oder } \\
\text { reg.sprach. }\end{array}$ \\
\hline \multicolumn{7}{|l|}{ Provinz Ostpreußen } \\
\hline Masuren 1 & 805 & 68651 & 474 & \multirow{2}{*}{49823} & 70 & 4582 \\
\hline $\begin{array}{l}\text { Südliches } \\
\text { Ermland?2 }\end{array}$ & 11521 & 14465 & 4915 & & 1045 & 2940 \\
\hline $\begin{array}{l}\text { Westpreußen } \\
\text { (Abstimmungs- } \\
\text { gebiet) }\end{array}$ & 5951 & 5895 & 1635 & 4193 & 953 & 2539 \\
\hline $\begin{array}{l}\text { Provinz Grenzmark } \\
\text { Posen-West- } \\
\text { preuBen }{ }^{3}\end{array}$ & 8319 & 4965 & 6357 & 3194 & 6682 & 2039 \\
\hline $\begin{array}{l}\text { Provinz Ober- } \\
\text { schlesien }\end{array}$ & 151162 & 384572 & 99193 & 266375 & 3731 & 36765 \\
\hline Summe & 177758 & 478548 & 112574 & 323585 & 12481 & 48865 \\
\hline Summe je Zählung & \multicolumn{2}{|c|}{656306} & \multicolumn{2}{|c|}{436159} & \multicolumn{2}{|c|}{61346} \\
\hline
\end{tabular}

${ }^{1}$ Kreis Oletzko im Reg. Bez. Gumbinnen und die Kreise Johannisburg, Lötzen, Lyck, Neidenburg, Ortelsburg. Osterode und Sensburg im Reg. Bez. Allenstein

2 Land- und Stadtkreis Allenstein sowie Kreis Rössel

${ }^{3}$ Angaben für 1939 nach dem territorialen Bestand von 1925

Die Tabelle zeigt einen ständigen Rückgang des polnischen Bevölkerungselementes in den östlichen Randzonen, zuletzt sogar ein radikales Absinken, wobei die Zahlen für 1939 nicht mehr ernst zu nehmen sind, selbst wenn man den damals rücksichtslos vorgetragenen NS-Terror gegen die polnische Grenzbevölkerung in Rechnung stellt, der ein offenes Bekenntnis zum Polentum zu einem echten Risiko hatte werden lassen. Doch unbeschadet dieser Zuspitzung stellt sich grundsätzlich die Frage, wieweit das Bekenntnis zum Polentum überhaupt ausreicht, um das tatsächliche Volumen polnischsprachiger Bevölkerungsgruppen an der deutsch-polnischen Grenze angemessen zu erfassen und ob denn das ethnische Substrat der Polen im selben Maße abgenommen hat wie ihr nationalpolitisches Votum. Die Frage kompliziert sich noch durch das dynamische Nebeneinander von Einsprachigkeit, Zweisprachigkeit und Regionalsprachen. Auch über diesbezügliche Verschiebungen gibt die obenstehende Tabelle Aufschluß. Dem generell kleineren Teil reiner polnischer Muttersprachler mit abnehmender Tendenz steht eine wachsende Anzahl von Zwei- und Regionalsprachigen entgegen. Die bemerkenswerte

\footnotetext{
6 Zusammengestellt von Mathias Niendorf nach Zieliniski. Henryk: Z problematyki narodowościowej na pograniczu polsko-niemieckim w dobie międzywojennym, in: Przeglad Zachodni 5 (1949). Nr. 9-10, S. 263-272 (Tabelle S. 267); Bohmann. S. 225-239.
} 
Ausnahme der Provinz Grenzmark Posen-Westpreußen wird man auf die traditionell engeren Bindungen zu den rein polnisch besiedelten Gegenden der ehemaligen Provinz Posen zurückführen dürfen.

Deutlich wird auf jeden Fall ein ethnisches Ausfransen an der deutsch-polnischen Grenze mit fließenden übergängen und einer generellen Tendenz zu einer wenigstens partiellen Anpassung an die herrschende Staatsnation und -sprache. Es gab gerade bei der polnischen Grenzminderheit viel Opportunismus und Scheinanpassung an das deutsche Milieu, in den Städten mehr als auf dem Land. Der alltägliche Umgang mit deutschen Behörden, Arbeitgebern usw. schuf unvermeidliche Brücken für ein solches Taktieren. Mischehen verwischten die ethnischen Trennlinien. So waren es häufig Angehörige ethnisch gemischter Familienverbände, die sich in ihrem nationalen Bekenntnis bedeckt oder inkonsequent verhalten haben. Solche Positionen entzogen sich von vornherein einer definitiven ethnischen Zuordnung. Auch Volkszählungen und Stimmabgabe bei den Wahlen boten den Aufsichtsbehörden keine wirklich zuverlässigen Anhaltspunkte. Die Schwelle der freiwilligen Assimilierung bzw. der mehr oder weniger erzwungenen Germanisierung, nach deren Überschreiten ein Pole zu einem Deutschen geworden war, läßt sich gerade in den Grenzgebieten kaum ermitteln. Die neuere Geschichte Oberschlesiens bietet außerdem ein anschauliches Beispiel dafür, daß ein solches Überwechseln keineswegs ein unumkehrbarer Weg zu sein brauchte. Der zeitgenössische deutsche Terminus „schwebendes Volkstum" trifft die ethnisch diffuse Situation im deutsch-polnischen Grenzbereich vielleicht noch am besten. ${ }^{7}$

Die große Zahl „schwankender Elemente“ an der Ostgrenze, wie die national nicht eindeutig zu definierenden Bevölkerungsgruppen im damaligen amtlichen Sprachgebrauch bezeichnet worden sind, war nur vordergründig ein statistisches Problem. Tatsächlich ging es um noch offene Integrationsprozesse entweder in Richtung Assimilation an das deutsche Mehrheitsvolk oder in Richtung Separation hin zur polnischen Minderheit. Man darf ohne Übertreibung behaupten, daß von der Haltung eben dieser ethnischen Zwischenschicht das nationale Kräfteverhältnis in den Grenzgebieten abhängig gewesen ist.

In diesem Zusammenhang ist außerdem darauf hinzuweisen, daß die klassische konfessionelle Trennlinie zwischen protestantischen Deutschen und katholischen Polen in den hier interessierenden Grenzgebieten höchstens für die Provinz Grenzmark PosenWestpreußen gegolten hat, in Ostpreußen schon mit Einschränkungen, da die masurische Bevölkerung evangelischen Glaubens war. Im Ermland und vor allem in Oberschlesien war wiederum die Zugehörigkeit zur katholischen Kirche nationenübergreifend, so daß auch von der konfessionellen Seite her keine absoluten nationalen Unterscheidungskriterien vorgegeben gewesen sind.

Über die soziale Gliederung der polnisch- bzw. teilweise polnischsprachigen Grenzbevölkerung lassen sich nur ungefähre Aussagen treffen. ${ }^{8}$ Fest steht lediglich, daß es sich mehrheitlich um Unterschichten gehandelt hat. Kleinbauern, Landarbeiter, Häusler und nur vereinzelt Gutsbesitzer stellten den Grundstock der überwiegend ländlichen Bevölkerung. In den wenigen Städten waren Polen vor allem als Arbeiter beschäftigt. Hinzu kamen noch einige wenige Handwerker und kleine Kaufleute. Wenn man von

\footnotetext{
7 Siehe Beck, Robert: Schwebendes Volkstum im Gesinnungswandel. Stuttgart 1938; außerdem Boehm, Max Hildebert: Das eigenständige Volk. Göttingen 1932, S. $130 \mathrm{ff}$.

$8 \mathrm{Vgl}$. Wrzesiniski: Ruch polski, S. 25-27, 37-39, 48-50.
} 
den katholischen Geistlichen und den Lehrern einmal absieht, gab es in diesen Regionen fast keine polnischen Eliten. Eine ganze Reihe der ohnehin nicht zahlreichen polnischen Gutsbesitzer, Kaufleute und Großbauern hatte unmittelbar nach Kriegsende ihre ursprüngliche Heimat verlassen, um in dem wiedergegründeten polnischen Staat eine neue Existenz aufzubauen. Polnischen Schätzungen zufolge waren es ca. 80000 Personen dieser wohlhabenderen Schichten, die zwischen 1919 und 1923 diesen Weg gegangen sind, wobei das durch das Versailler Vertragswerk vorgesehene Optantenschema nur eine formalisierte Spielart dieser Abwanderung gewesen ist. Es fehlte somit an bodenständigen Wortführern eines polnischen Nationalbewußtseins in den Grenzgebieten. Polnische Organisatoren und Redner aus Posen, Berlin oder dem Ruhrgebiet konnten diesen Mangel nicht wirklich ausgleichen, weil sie von der Grenzbevölkerung nicht immer als Sprecher ihrer spezifischen Belange anerkannt worden sind.

Die polnische Grenzminderheit kann demnach als ökonomisch und sozial schwach, als beinahe führungslos und im ganzen wenig nationalbewußt bezeichnet werden. Das waren die nicht gerade beneidenswerten Ausgangspositionen für eine Minderheit, die außerdem nicht in einem zusammenhängenden Siedlungsgürtel wohnte und von ethnischen Aufweichungserscheinungen gekennzeichnet gewesen ist. An diesen inneren Vorausetzungen sollte sich während der gesamten Zwischenkriegszeit nichts Wesentliches ändern und dementsprechend schwierig gestaltete sich die Bewahrung und Verteidigung polnischer Eigenart in den Grenzgebieten.

Rechtliche Grundlage dafür bildete einmal der Artikel 113 der Reichsverfassung, der „den fremdsprachigen Volksteilen des Reiches“ völlige Rechtsgleichheit und die „freie Entfaltung ihrer volkstümlichen Entwicklung“ zusicherte, besonders beim Gebrauch der Muttersprache in Unterricht, innerer Verwaltung und vor Gericht. ${ }^{9}$ Einen ähnlichen Sprach- und Schulpassus enthielt der Artikel 73 der Preußischen Verfassung vom 30. November 1920. In dieselbe Richtung wiesen gleichfalls die Erlasse des Preußischen Ministers für Wissenschaft, Kunst und Volksbildung über den Gebrauch der polnischen Sprache in den Schulen, die sukzessiv für alle Grenzprovinzen zwischen 1918 und 1925 herausgegeben worden sind. Welchen zentralen Stellenwert der Schulfrage in der Gesetzgebung und in den einschlägigen Verordnungen beigemessen worden ist, belegt auch die in der deutschen Öffentlichkeit heftig umstrittene preußische Ordnung zur Regelung des Schulwesens für die polnische Minderheit vom 31. Dezember 1928, die den Polen die Errichtung privater Minderheitenschulen zugestanden hat. ${ }^{10}$ Zuvor hatte es nur in Oberschlesien polnische Schulen gegeben.

Aus dem Rahmen fiel demgegenüber das deutsch-polnische Oberschlesien-Abkommen, vom 15. Mai 1922, weil es den innerstaatlichen Bezugsrahmen überschritten und einen umfassenderen, international kontrollierbaren Minderheitenschutz gewährleistet

\footnotetext{
9 Und zum Folgenden Baier, S. 221-223 sowie die ausfürliche Dokumentation von Müller, Helmut: Die polnische Volksgruppe im Deutschen Reich, ihre Stellung in Verfassung und Verwaltung seit 1871. Diss. Rostock 1938. S. 126-167.

10 Siehe dazu Broszat, Martin: Außen- und innenpolitische Aspekte der preußisch-deutschen Minderheitenpolitik in det Ära Stresemann. Dargestellt an der Genesis der preuBischen ..Ordnung zur Regelung des Schulwesens für die polnische Minderheit" vom 31. Dezember 1928. In: Kluxen, Kurt u. Mommsen, Wolfgang (Hg.): Politische Ideologien und nationalstaatliche Ordnung. Festschr. f. Theodor Schieder. München/Wien 1968 , S. $393-445$
} 
hat. Darin war u. a. den polnischen Bevölkerungsteilen Westoberschlesiens ein institutionalisiertes Beschwerderecht zugestanden und Deutschland vertraglich an den europäischen Minderheitenschutz angeschlossen worden. " Nach Ablauf der Gültigkeit dieses Abkommens im Jahre 1937 kam es dann ersatzweise - auf die gesamten polnischen bzw. deutschen Minderheiten bezogen - zu getrennten, aber gleichlautenden Minderheitenerklärungen der deutschen und der polnischen Regierung, die letztlich unverbindlich und völlig losgelöst vom Völkerbund abgegeben worden sind. Diese Erklärungen versprachen den jeweiligen Minderheiten bei loyalem Verhalten alle Rechte und Freiheiten zu ihrer kulturellen und wirtschaftlichen Entfaltung und enthielten sogar ein ausdrückliches Assimilierungsverbot. - Somit läßt sich durchaus eine positive Bilanz der rechtlichen Lage ziehen. Auch wenn den Polen in Deutschland keine kollektiven Sonderrechte im Sinne irgendeiner Autonomie zugestanden worden sind, sondern nur eine individuelle Gleichstellung mit den übrigen Staatsangehörigen, so hatten sich die rechtlichen Rahmenbedingungen für eine polnische Interessenvertretung im Vergleich zur Vorkriegszeit doch insgesamt eindeutig zum Besseren gewendet. Wie ist dieser gesetzlich garantierte Handlungsspielraum nun praktisch ausgefüllt worden?

Relativ schwach war das Engagement der Polen bei Parlaments- und Kommunalwahlen, nur während der Wahlkämpfe formierten sich überhaupt politische Vereinigungen wie die „Polska Partia Ludowa“ (Polnische Volkspartei), alternierend auch „PolskoKatolicka Partia Ludowa“ (Polnisch-Katholische Volkspartei) genannt. ${ }^{12}$ Für eine dauerhafte Etablierung polnischer politischer Parteien fehlten an der Grenze schlichtweg die Voraussetzungen. Der Mangel an entsprechend motivierten bodenständigen Eliten war sicherlich ein wichtiger, aber nicht der einzige Grund dafür. Nicht zu unterschätzen ist ferner die Tatsache, daß gerade die an der Grenze wohnenden Polen einer besonders wachsamen und miBtrauischen Überwachung von seiten der örtlichen Aufsichtsorgane unterlagen. Vorsichtige Zurückhaltung in politischen Angelegenheiten war somit ein Gebot der Vernunft und schützte vor dem Verdacht illoyalen Verhaltens. Außerdem war mit und in den kleinen Lebenswelten dieser Randgebiete keine „große Politik“ zu machen. Wenn es hier um polnische Belange ging, so handelte es sich in der Regel um ganz praktische Fragen der kulturellen und wirtschaftlichen Selbstbehauptung, die wiederum energisch angegangen worden sind.

Zentrales Aktionsfeld des organisierten Polentums in den Grenzgebieten während der Zwischenkriegszeit war zweifellos das Ringen um die Anerkennung und Pflege der polnischen Sprache in Schule und Unterricht. Dabei ging es um die Möglichkeit polnischen Sprachunterrichtes an deutschen Schulen, um die Erlaubnis polnischer Unterrichtssprache an staatlichen Schulen in bestimmten Fächern (Religion), um die Zulassung polnischer privater Minderheitenschulen und Kindergärten sowie um Stipendien für polnische Studenten. Als einschlägige Interessenvertretung trat der „Verband der polnischen Schulvereine in Deutschland" (Związek Polskich Towarzystw Szkolnych w Niemczech) auf, der 1922 gegründet wurde und später vor allem in seinen örtlichen Zweigstellen - den „Towarzystwa Szkolne“ - bei der Gründung von polnischen Minderheitenschulen aktiv geworden ist. ${ }^{13}$

11 Dazu ausführlich Krasuski, S. $68 \mathrm{ff}$.

12 Und zum Folgenden Wrzesiriski: Ruch polski, S. 61 f., 69 f., $122 \mathrm{ff}, 181 \mathrm{ff}$.

13 Und zum Folgenden Baier, S. 238 ff.; Lis, Michal: Zwiazek Harcerstwa Polskiego w Niemczech 1922-1939. Opole 1987; Pietrzak-Pawtowski. Kazimierz: Spółdzielczość polska na Ziemiach Zachodnich i Północnych 1918-1939. Warszawa 1967; Wrzesiński: Ruch polski, S. 139 ff., 190 ff. 
Der Pflege der polnischen Sprache und Kultur dienten auch andere kulturelle Vereinigungen wie z. B. die religiös-nationalen Frauenkongegrationen der Heiligen Kinga oder die sehr aktiven polnischen Gesangsvereine in Oberschlesien. Hervorzuheben ist in diesem Zusammenhang auch das dichte Netz polnischer Jugendorganisationen, allen voran die polnischen Pfadfinder, die seit 1925 zentral in dem ,Związek Harcerzy Polskich w Niemczech" (Verband der polnischen Pfadfinder in Deutschland) zusammengeschlossen waren und die seit Mitte der dreiBiger Jahre besonders in den Grenzgebieten einen erstaunlich hohen Zuwachs an Mitgliedern verzeichnen konnten (1939: 2620 Mitglieder).

Die materielle Absicherung der polnischen Grenzbevölkerung betrieben die „Banki Ludowe“" (Volksbanken) und „Rolniki“ (Landmänner), erstere durch die Vergabe von Krediten im Falle von Verschuldungen, Haus- oder Grundstückserwerb, letztere als landwirtschaftliche Ein- und Verkaufsgenossenschaften. Meist noch in der Vorkriegszeit gegründet, haben nur sehr wenige dieser genossenschaftlichen Zusammenschlüsse mit ihren durchweg bescheidenen Kapitaleinlagen Inflation und Weltwirtschaftskrise überstanden - trotz eigener Zentralisierungsbemühungen und trotz der Unterstützung durch Warschauer Regienungstellen. Dabei ist freilich einzukalkulieren, daß ihre eigentliche Bedeutung schon in den vorausgegangenen Jahrzehnten mehr in ihrem gemeinschaftsfördernden Anliegen als in ihrer ökonomischen Leistungskraft gelegen hat.

Wie die Genossenschaften konnten auch viele andere polnische Organisationen an Formen des Vereinslebens im Kaiserreich anknüpfen. Das trifft beispielsweise auch für die entsprechenden Ortsgruppen des nationalpolnischen Turnerverbandes "Sokol“" zu, der in den Berichten wiederholt erwähnt wird. Neu war demgegenüber die Schaffung eines zentralen polnischen Minderheitenverbandes im Jahre 1922, der den Namen „Związek Polaków w Niemczech" (Bund der Polen in Deutschland) trug und in den amtlichen Berichten meist abgekürzt als „Polenbund“ bezeichnet worden ist. ${ }^{14}$ Ungeachtet regionaler Untergliederungen ist er straff zentralistisch von Berlin aus geführt worden. Die Tatsache, daß die Verbandsspitze fast ausschließlich von Funktionären aus dem Ruhrgebiet und der Berliner Polenkolonie beherrscht wurde, die in sehr abgehobener Weise einen abstrakten klassen- und regionenüberschreitenden Solidarismus vertreten haben und gegenüber Warschau keine selbständige Position behaupten konnten, hat Anfang der dreißiger Jahre zur Formierung oppositioneller Gruppierungen geführt, in Oberschlesien 1936 sogar zur vorübergehenden Abspaltung eines „Związek Polaków na Śląsku“ (Bund der Polen in Schlesien). Am Beispiel des Polenbundes, zweifellos der größten und einflußreichsten polnischen Vereinigung in Deutschland, können die Schwierigkeiten und Grenzen einer organisierten polnischen Interessenvertretung exemplarisch abgelesen werden: Selbst in seinen besten Zeiten zählte der Verband nie mehr als ca. 50000 Mitglieder. Programmatische Leitlinie für diese polnische Koordinationsinstanz in Deutschland war die Einhaltung einer strikten Loyalität zum deutschen Staat und die Anerkennung der gültigen Staatsgrenzen. Auf dieser Basis baute der Polenbund auch seine Bündnispolitik im Rahmen des 1924 von polnischer Seite initiierten "Verbandes der nationalen Minderheiten in Deutschland" auf, ebenso seine Kontakte zu Warschauer Regierungsstellen. Offizielles Verbandsorgan des Polenbundes war die Monatsschrift „Polak w Niemczech“ (Der Pole in Deutschland) mit Beilagen für Schulkinder und Jugendliche.

14 Vgl. dazu ausführlich Wrzesiriski: Ruch polski, S. 56 ff., 318 ff;; zusammenfassend ders.: Die polnische Bevölkerung in der Weimarer Republik. In: W. Jacobmeyer ( $\mathrm{Hg}$.): Die deutsch-poinischen Beziehungen 1919-1939. Braunschweig 1985, S. 91-95. 
Darüber hinaus bemühte sich der Polenbund, die polnische Presse in Deutschland zu zentralisieren, was u.a. durch die Gründung einer Presseagentur (Centrala Prasowa) in Berlin zum Ausdruck kam, die alle Redaktionen mit gleichlautendem Informationsmaterial versorgen sollte. Der damit zwangsläufig verbundene Verlust an regionalem Profil ist aber von der Leserschaft nicht akzeptiert worden. In Ostpreußen konnte sich daneben die vergleichsweise unabhängige und traditionsreiche „Gazeta Olsztyńska“ (Allensteiner Zeitung - Auflage 1922-1932: zwischen 1000 und 2000 Exemplare) seit 1929 mit der speziellen Beilage „Głos Pogranicza“ (Grenzlandstimme) behaupten. ${ }^{15}$ Oberschlesien verfügte ohnehin über eine sehr vielfältige und eigenständige regionale Presselandschaft.

Zusammenfassend kann behauptet werden, daß die Polen in Deutschland und in seinen Grenzregionen über eine reiche Palette von Artikulations- und Organisationsmöglichkeiten verfügt haben, daß diese Möglichkeiten um so effektiver genutzt worden sind, je mehr sie aus spezifisch regionalen Bedürfnislagen heraus entstanden waren und unterhalten worden sind, daß generell Zentralisierungsversuche jeder Art entweder nicht dauerhaft gelungen sind oder zu erheblichen Spannungen innerhalb der Polenbewegung geführt haben und daß ein eher unpolitscher Grundzug als hervorstechendes Merkmal festzuhalten ist.

Für die grundsätzlichen Einstellungsmuster der polnischen Grenzminderheit waren mehrere Faktoren von ausschlaggebender Bedeutung, die in ihrer Wirkung nicht immer übereinstimmten. Da war einmal der Umstand, daß diese Bevölkerungsgruppen - wie schon vor dem Kriege - Minderheit geblieben waren, d. h. ihren Status nicht geändert hatten. Damit ist zugleich der entscheidende Unterschied zu dem Rollenwechsel benannt, den die Deutschen jenseits der deutsch-polnischen Grenze nach dem Kriege hinzunehmen gezwungen gewesen sind. ${ }^{16}$ Die polnische Minderheit in Deutschland brauchte sich nicht auf eine neue Obrigkeit einzustellen, sie war ihr prinzipiell vertraut, selbst in ihren Unterdrückungsmechanismen. Der staatliche und gesellschaftliche Bezugsrahmen war derselbe geblieben und von seiner Demokratisierung nach 1918 durften sich die noch in Deutschland lebenden Polen sogar eine Verbesserung ihrer rechtlichen Lage erhoffen.

Für die polnische Grenzminderheit bestand so besehen kein Anlaß, besonders aufgeregt auf ihre Situation zu reagieren und ihre bisherigen Einstellungen und Lebensumstände zu verändern. Andererseits war sie als Restminderheit von ihren Landsleuten jenseits der Grenze abgeschnitten worden, und allein durch diesen Umstand einer größeren Marginalisierungs- und Entnationalisierungsgefahr ausgesetzt als vor dem Kriege. Dabei spielte nicht nur die zahlenmäßige Verringerung des polnischen Bevölkerungselementes eine Rolle, sondern auch der Umstand, daß mit dieser Abschnürung eine Abwanderungsbewegung gerade der wirtschaftlich potentesten und gesellschaftlich aktivsten Polen in den neu gegründeten Staat einher gegangen ist, welche den plebejischen Charakter der polnischen Grenzminderheit noch verstärkt hat.

15 Siehe Wakar, Andrzej u. Wrzesiński, Wojciech: „Gazeta Olsztyńska“ 1886-1939. Olsztyn 1986, S. 238 f., 272, 279 und zum Folgenden Smotka, Leonard: Prasa polska na Sląsku Opolskim 1922-1939. Wroclaw 1976.

$16 \mathrm{Vgl}$. dazu die Einleitung von Marian Wojciechowski in diesem Band; auBerdem Rexheuser, S. 16-18; Riekhoff, S. 194-196; Wynot, Edward: The Polish Germans 1919-1939: National Minority in a Multinational State: In: The Polish Review XVII (1972) Nr. 1, S. 30-34. 
Die nach 1918 eingetretenen Veränderungen dürfen indes nicht überschätzt und nur auf ihre negativen Wirkungen hin interpretiert werden. Schließlich hat die hier interessierende und dokumentierte polnische Grenzbevölkerung schon vor dem Kriege an der Peripherie polnischer Siedlungsgebiete gelebt. Ihnen ist schon damals im nationalen Leben der polnischen Teilgesellschaft unter preußisch-deutscher Herrschaft keine übermäßige Bedeutung zugekommen. So war die nationalpolnische Bewegung in Oberschlesien und Ostpreußen vor dem Kriege relativ spät und keineswegs immer erfolgreich in Erscheinung getreten und auch die Gegenstrategien der Ostmarkenpolitik und -propaganda der Wilhelminischen Ära hatten hier keine besonders lohnenden Ansatzpunkte gesehen.

Mit der Wiederbegründung eines souveränen polnischen Staates und der Ziehung der deutsch-polnischen Grenze war freilich ein neues Element im Bewußtsein der bei Deutschland verbliebenen polnischen Siedlungsgruppen hinzugekommen. Allein die Existenz eines polnischen Staates jenseits der Grenzen mußte bei ihnen zu einer Hebung des eigenen NationalbewuBtseins führen und schon in Gang befindliche Assimilationsprozesse aufhalten, wenn nicht sogar rückgängig machen. Unmittelbar nach dem Kriege äußerte sich dieses gesteigerte Selbstbewußtsein noch in der Hoffnung auf einen baldigen AnschluB an Polen. Aber auch nachdem sich diese Hoffnungen als unerfüllbar erwiesen hatten, blieb die stolze Zuversicht, mit dem Minderheitenstatus nicht allein gelassen zu sein, sondern als Auslandspolen ethnisch einem Staatsvolk verwandt zu sein, das zudem in unmittelbarer geographischer Nähe präsent war und auf dessen Rückendeckung man gerade bei der Wahrung der nationalen Eigenar im Rahmen des Deutschen Reiches glaubte zählen zu dürfen. Der psychologische Effekt eben dieser Rückendeckung, ob tatsächlich gewährt oder nur gewünscht, scheint jedenfalls - folgt man dem Urteil der örtlichen und regionalen deutschen Grenzbehörden - über den gesamten Zeitraum der Zwischenkriegszeit lebendig gewesen zu sein.

Dieser Erwartungshaltung ist von seiten der Warschauer Regierungen nur sehr zurückhaltend, unzureichend und vor allem mit erheblicher Verzögerung entsprochen worden. Die ersten dauerhaften Verbindungslinien sind vielmehr auf regionaler und gesellschaftlicher Ebene hergestellt worden. Vor allem ist hierbei der westpolnische Zweig der Nationaldemokraten mit seiner Publizistik zu nennen, der lautstark für eine Eingliederung der bei Deutschland verbliebenen polnischen Restminderheiten eingetreten ist. Der von diesen Kreisen maßgeblich bestimmte ,Związek Obrony Kresów Zachodnich" (Verband zur Verteidigung der Westgebiete), 1921 gegründet und aus den Abstimmungskämpfen in Oberschlesien hervorgegangen, erstreckte seine Tätigkeit in Absprache mit amtlichen Stellen auch auf die Polen jenseits der Grenze, u. a. durch die Organisierung von Gruppenreisen nach Polen, durch die Einrichtung von Sommerschulen, Berufspraktika u. ä. m. ${ }^{i 7}$

Das minderheitenpolitische Engagement der Nationaldemokraten und des polnischen Westmarkenverbandes darf vor allem in seiner öffentlichkeitswirksamen Bedeutung nicht unterschätzt werden. Genauso verkehrt wäre es aber, die regionale Schwerpunktbildung in den angrenzenden Wojewodschaften außer acht zu lassen oder gar eine Deckungsgleichheit mit der offiziellen Haltung der Warschauer Regierungen zu unterstellen. ${ }^{18}$ Ein offensiv nationalpolitisches Interesse am Schicksal der bei Deutschland

17 Und zum Folgenden Mroczko, Marian: Zwiazek Obrony Kresów Zachodnich 1921-1934. Gdańsk 1977. besonders S. 176 ff.: ders. Polska myśl zachodnia 1918-1939. Poznań 1986, S. 108 ff.

18 Grundlegend jetzt Chalupczak, Henryk: Il Rzeczpospolita a mniejszość polska w Niemczech. Poznań 1992 , S. $26 \mathrm{ff}$ 
verbliebenen polnischen Restminderheiten in den Grenzregionen hat es lediglich in der Zeit unmittelbar nach Kriegsende gegeben, als diverse Gebietszugehörigkeiten (wie z. B. Ostpreußen und Oberschlesien) noch nicht völlig geklärt waren. So war vor allem während der Abstimmungskämpfe in den umstrittenen Grenzgebieten ein sehr direktes Hineinwirken Warschauer Regierungsstellen zu spüren gewesen. Später flauten diese Art von Aktivitäten völlig $a b$, so daß für den überwiegenden Zeitraum zwischen den beiden Weltkriegen kaum von einer Irredentapolitik des polnischen Staates gesprochen werden kann. Das war schon allein deswegen schlecht möglich, weil für alle polnischen Regierungen die Unantastbarkeit der polnischen Westgrenze zu den Grundpfeilern der territorialen Integrität des polnischen Staates gehört hat. Außerdem standen für Polen schwierige Probleme der Innen- und Außenpolitik im Vordergrund. Der polnische Staat befand sich zudem in finanziellen Dauernöten, so daß allein von der materiellen Seite her an keine den tatsächlichen Bedürfnissen entsprechende Unterstützung der polnischen Grenzminderheiten zu denken war.

Mitte der zwanziger Jahre sind überhaupt erst entsprechende Konzepte unter der Führung des polnischen Außenministeriums erarbeitet worden. Damals wurde mit der Koordination beteiligter Behörden (u. a. der Grenzwojewodschaften) und gesellschaftlicher Vereinigungen ( $u$. a. des polnischen Westmarkenverbandes) begonnen und eine kontinuierliche Förderung eingeleitet. Die Schwerpunkte dieser Unterstützungsarbeit lagen dabei unmißverständlich auf wirtschaftlichem und kulturellem Gebiet, wobei die Grenzminderheiten generell mit größeren Zuwendungen bedacht worden sind. Vor allem Minderheitenschulen und Genossenschaften sind kontinuierlich unterstützt worden. Politische Aktivitäten sind demgegenüber nur episodisch, vornehmlich im Zusammenhang von Parlaments- und Kommunalwahlen, gefördert worden. Doch auch in dieser Phase war eine reibungslose Kooperation zwischen den Warschauer Sanacja-Regierungen nach 1926 und der ihnen nahestehenden zentralen Leitung des Polenbundes in Deutschland auf der einen und der überwiegend nationaldemokratisch oder christdemokratisch gestimmten polnischen Grenzbevölkerung auf der anderen Seite nicht immer gegeben.

Unbeschadet solcher Schwierigkeiten und Differenzen war die finanzielle Unterstützung, welche der polnischen Minderheit im allgemeinen und den Grenzminderheiten im besonderen von seiten des polnischen Staates zuteil geworden ist, doch beachtlich, zumal wenn sie in Relation zu dem Gesamtaufwand für das Auslandspolentum gesetzt wird. So hat beispielsweise die Konsularabteilung des polnischen Außenministeriums im Rechnungsjahr 1935/36 für die Unterstützung der im Ausland lebenden Polen insgesamt 4320000 Zloty ausgegeben und von dieser Seite waren immerhin 2681400 Zloty, d.h. 62,07\% nach Deutschland geflossen (1 Złoty $=50$ Reichspfennige). ${ }^{19}$

Diese Bevorzugung läBt sich nur mit der politischen Bedeutung erklären, welche die Warschauer Regierungen der polnischen Minderheit in Deutschland für die Gestaltung der deutsch-polnischen Nachbarschaftsbeziehungen beigemessen haben. $\mathrm{Ob-}$ wohl ein unmittelbares staatliches Interesse und ein übermäßiges Engagement für die in Deutschland lebenden Polen aufs Ganze gesehen eher bezweifelt werden kann, nutzten die Warschauer Regierungen die Präsenz polnischer Bevölkerungsteile in Deutschland, um die deutschen Revisionsforderungen und Klagen über die schlechte Behandlung der deutschen Minderheit in Polen besser konterkarieren zu können. So hat eine systematische staatliche Förderung der in Deutschland lebenden Polen bezeichnenderweise

19 Ebenda, S. 117. Anm. 14; außerdem S. $11 \mathrm{ff}$. 
erst Mitte der zwanziger Jahre eingesetzt, also zeitgleich mit den minderheitenpolitischen Initiativen der deutschen Regierung auf der internationalen Bühne. Wie für die deutsche Politik, so ist auch für das offizielle Polen die polnische Minderheitenfrage in Deutschland kein primäres, sondern ein abgeleitetes Problem gewesen, dessen man sich bediente, um andere, übergeordnete Ziele besser und wirkungsvoller verfolgen zu können.

\section{Grundzüge der deutschen Minderheitenpolitik und -über- wachung in den Grenzgebieten}

Vor dem Ersten Weltkrieg hatten die polnischen Bevölkerungsteile in Deutschland noch knapp 4 Millionen gezählt, das waren ca. 6,2\% der gesamten Reichsbevölkerung und immerhin ca. $10 \%$ der Einwohner Preußens. Die Polen waren damit die größte nichtdeutsche Bevölkerungsgruppe im Kaiserreich. Die sogenannte Polenfrage bzw. das „polnische Gemeinwesen im preußischen Staat", wie die gutorganisierte polnische Teilgesellschaft unter preußisch-deutscher Herrschaft damals bezeichnet worden ist, stellten für Politik und öffentliche Meinung ein kardinales Integrationsproblem dar, dem man zuletzt nur noch mit Hilfe drakonischer Ausnahmegesetze beizukommen glaubte. ${ }^{20}$ Die Rigorosität dieser letztlich vergeblichen Germanisierungsbestrebungen war freilich schon damals von einem exklusiven Nationalstaatsdenken gelenkt worden, in dem prinzipiell kein Platz für ein gleichberechtigtes Nebeneinander verschiedener Nationalitäten vorgesehen war. Nach 1918 hatte dieses Denkschema infolge des Zusammenbruches der Großreiche in Mittel- und Osteuropa noch an Zugkraft gewonnen, nicht zuletzt beim neuen Nachbarstaat Polen.

Für Deutschland hatten die Kriegsfolgen unter ethnischen Gesichtspunkten nur eine weitere Vereinheitlichung der Staatsbevölkerung mit sich gebracht; d.h. Deutschland war weniger als zuvor ein Minderheitenstaat. Die nichtdeutschen Bevölkerungsteile, also die Polen, die Sorben, die Litauer, die Friesen und Dänen machten zusammengenommen nicht mehr als 2,05\% der Gesamtbevölkerung Deutschlands aus (Stand: 1925) und in Preußen betrug dieser Anteil auch nur 3\%. ${ }^{21}$ Mit Abstand die stärkste Gruppe bildeten dabei allerdings die Polen im Deutschen Reich. Sie stellten 1,58\% der Gesamtbevölkerung, wobei wiederum die polnische Grenzbevölkerung im Osten wie schon vor dem Kriege numerisch vor den polnischen Auswandererkolonien in Mittel- und Westdeutschland rangierte. Die Kerngebiete und Zentren der nationalpolnischen Bewegung, vor allem die Provinz Posen, waren aber größtenteils an Polen gefallen, so daß die polnische Restbevölkerung in den Grenzgebieten weder zahlenmäßig noch wirtschaftlich oder politisch ein wirklich ernstzunehmendes Thema der Innenpolitik sein konnte.

20 Aus der Fülle der Literatur hier nur stellvertretend Broszat: Zweihundert Jahre, S. 161 ff.; Trzeciakowski, Lech: Pod pruskim zaborem 1850-1918. Warszawa 1973, S. 285 ff.; Wehler, Hans-Ulrich: Polenpolitik im Deutschen Kaiserreich 1871-1917. In: Ders.: Krisenherde des Kaiserreichs 1871-1918. Göttingen 1970, S. $190 \mathrm{ff}$.

21 Nach Keller, Karl: Die fremdsprachige Bevölkerung in den Grenzgebieten des Deutschen Reiches. Berlin 1929, S. 42-46. 
Wie schon dargelegt wurde, sind die rechtlichen Rahmenbedingungen für die in Deutschland lebende polnische Minderheit gar nicht so unvorteilhaft gewesen, wenngleich die vorbildlichen Verfassungsartikel nur unzureichend durch einige wenige und dazu noch sehr allgemein gehaltene Ausführungsbestimmungen ergänzt worden sind. Auf diese Weise war den zuständigen regionalen Verwaltungsbehörden ein großer Ermessens- und Handlungsspielraum eingeräumt, der im Zuge der allgemein gespannten deutsch-polnischen Beziehungen jener Jahre zu repressiven Maßnahmen ausgenutzt werden sollte - eine Praxis, die übrigens auch in anderen europäischen Staaten, nicht zuletzt in Polen, üblich gewesen ist. Insofern fällt es schwer, die praktische Minderheitenpolitik und die tatsächliche Lage der polnischen Minderheit in Deutschland anhand der geltenden Rechtsnormen beschreiben und bewerten zu wollen.

Entscheidend war die Behördenpraxis vor Ort und die stand zwar in einer ständigen Wechselwirkung mit den Richtlinien der allgemeinen Minderheitenpolitik, entwickelte aber darüber hinaus eigene Gesetzmäßigkeiten, die nicht immer und vor allem niemals vollständig im Einklang mit den Berliner Vorgaben zu bringen gewesen sind. Von 1919 bis 1922 fand eine Reihe von Konferenzen der Innenministerien des Reiches und Preußens statt, die u.a. den künftigen politischen Kurs gegenüber den in Deutschland lebenden Polen festlegen sollten. ${ }^{22}$ Dabei ist aus sicherheitspolitischen Gründen sogar eine Beschneidung der allgemeinen Bürgerrechte für die polnische Grenzbevölkerung erwogen worden. In dieser unmittelbaren Nachkriegszeit sind es vor allem militärische Stellen und die zuständigen Provinzialverwaltungen gewesen, die ein solches drakonisches Vorgehen befürwortet haben.

SchlieBlich setzte sich als Generallinie eine weiche Variante durch. Insbesondere auf Drängen des Auswärtigen Amtes wurde eine offene Diskriminierung der polnischen Minderheit in Deutschland ausgeschlossen, um negative Rückwirkungen auf die ohnehin prekäre außenpolitische Position der Weimarer Republik im allgemeinen und auf die Situation der in Polen lebenden deutschen Minderheit im besonderen zu vermeiden. Statt einer frontalen Bekämpfung wurden die zuständigen regionalen Behörden dazu angehalten, die „Polenbewegung“" in ihrer organisatorischen Entwicklung diskret zu behindern und vor allem danach zu streben, die assimilationsbereiten und deutschfreundlichen Elemente zu gewinnen bzw. von den als radikal eingestuften Gruppierungen abzuspalten. Endziel war eine unauffallige, aber konsequente Assimilation der polnischen Restminderheit. Wenn dabei stets darauf geachtet werden sollte, den rechtsstaatlichen Rahmen zu wahren, so geschah dies vor allem aus Sorge vor auswärtigen Protesten. Nachdem Deutschland 1926 dem Völkerbund beigetreten und hier als Anwalt seiner Minderheiten aufgetreten war, ist ohnehin nur noch ein Vorgehen im Rahmen völkerrechtlich gültiger allgemeiner Minderheitenschutzbestimmungen möglich gewesen. ${ }^{23}$ Diese außenpolitisch diktierte Vorsicht reichte bis in die nationalsozialistische Ära hinein. Nach innen, d. h. auf die betroffene polnische Grenzminderheit bezogen, läßt sich ein situationsabhängiger Wechsel zwischen Repression und Assimilationsangeboten als durchgängiger Grundzug der Behördenpraxis konstatieren, also eine Politik von Zuckerbrot und Peitsche.

22 Und zum Folgenden Broszat: Innen- und auBenpolitische Aspekte, S. 401 ff.; Wrzesiński: Ruch polski, S. 43-45.

23 Vgl. dazu vor allem Pieper, Helmut: Die Minderheitenfrage und das Deutsche Reich 1919-1933/34. Hamburg 1974, S. $83 \mathrm{ff}$. 
Der entscheidende Unterschied zur polnischen Minderheitenpolitik gegenüber den in Westpolen lebenden Deutschen bestand wohl darin, daß die Haltung der deutschen und preußischen Regierungen und Behörden der polnischen Grenzminderheit gegenüber in viel stärkerem AusmaB abgeleiteter und reaktiver Natur gewesen ist, als dies umgekehrt der Fall war. Die Deutschen in Westpolen stellten aufgrund ihres hohen Organisationsgrades und ihres ökonomischen Gewichts für Staat und Verwaltung eine originäre Herausforderung dar, einen nicht ignorierbaren Faktor der polnischen Innenpolitik, mit dem man sich ernsthaft auseinanderzusetzen hatte. ${ }^{24}$ Die außenpolitische Aufladung durch die deutschen Revisionsansprüche spielte dabei eine wesentliche, aber nicht die einzige Rolle.

Umgekehrt war die polnische Minderheit in Deutschland im allgemeinen und die polnische Grenzminderheit im besonderen in jeder Hinsicht eine Quantité négligeable. Ihre brisante Bedeutung erhielt sie fast ausschließlich aus den gespannten Beziehungen zum polnischen Nachbarstaat und der Tatsache, daß jenseits der deutsch-polnischen Grenze Deutsche ebenfalls im Minderheitenstatus zu leben gezwungen waren und für die eigene Minderheitenpolitik damit von außen her Maßstäbe gesetzt worden sind. Viele Maßnahmen in diskriminierender und in liberalisierender Richtung, welche die polnischen Grenzminderheiten betroffen haben, waren explizit im Hinblick auf die deutsche Minderheit in Polen unternommen bzw. unterlassen worden, sei es als eine Vergeltungsaktion, sei es als ein konziliantes Entgegenkommen, um die Situation der Landsleute auf der anderen Seite der Grenze nicht zusätzlich zu erschweren. So besehen kann die deutsche bzw. preußische Minderheitenpolitik in den östlichen Grenzregionen als eine innenpolitische Verlängerung der deutschen Polen- und Ostpolitik eingestuft werden.

Diese Einschätzung behält auch dann ihre Gültigkeit, wenn man die innenpolitischen Bestimmungsfaktoren dieser Abwehrhaltung gebührend in Rechnung stellt. So ist die Minderheitenpolitik gegenüber den polnischen Bevölkerungselementen an der deutschpolnischen Grenze unbedingt im größeren Zusammenhang der ,,inneren Ostpolitik“ der Reichs- und preußischen Landesregierung zu interpretieren. ${ }^{25}$ Die schon zur Kaiserzeit evidente Krisenanfälligkeit und Stützungsbedürftigkeit der verschuldeten Landwirtschaft in den preußischen Ostprovinzen sowie die damit zusammenhängende „Ostflucht" aus diesen strukturschwachen Randgebieten hatten durch Krieg und neue Grenzziehung eine weitere Steigerung erfahren. Darum sind schon bald nach dem Krieg erneut Osthilfeprogramme entwickelt worden, zuerst für Ostpreußen, später für alle Ostprovinzen, die ab 1926 in systematische und großzügige Unterstützungsaktionen umgesetzt wurden. Neben Kredithilfen für landwirtschaftliche Betriebe, Handwerk und Handel, wurde der Wohnungs- und Schulbau gefördert, wurden Maßnahmen zur Wohlfahrts- und Gesundheitspflege eingeleitet und erneute Anstrengungen zu einer Ansiedlungspolitik unternommen.

Insbesondere der zuletzt genannte Programmpunkt, der übrigens am wenigsten realisiert werden konnte, war neben dem Ziel einer sozialen und wirtschaftlichen „Hebung“ dieser inneren Peripherien von einem ausgesprochen national- und minderheitenpolitischen Gesichtspunkt mitbestimmt. In einer einschlägigen Denkschrift der Reichskanzlei

24 Jetzt umfassend Blanke, Richard: Orpheans of Versailles. The Germans in Western Poland 1918-1939. Lexington 1993.

25 Siehe dazu Baier, S. 29 ff; 63 ff.; 221-223; Schulz, Gerhard: Staatliche Stützungsmaßnahmen in den deutschen Ostgebieten. In: Ders.: Das Zeitalter der Gesellschaft. München 1969, S. 252-298. 
vom Februar 1926 war unmißverständlich von der „Errichtung eines Bevölkerungsgrenzwalls an den deutschen Ostgrenzen“ die Rede, dessen Errichtung einer weiteren .,Verpolung" der Grenzgebiete vorbeugen und eine wirksame „Abwehr des slawischen Vorstoßes auf die deutsche Ostgrenze" sicherstellen sollte. ${ }^{26}$ Aus solchen Formulierungen sprach noch ganz der Geist der alten Ostmarkenpolitik, auch die Mittel zur Eindämmung der „polnischen Gefahr" waren weitgehend dieselben geblieben. Hinzugekommen war die Verbitterung über die an den wiedererrichteten polnischen Staat abgetretenen Ostgebiete und die ohnmächtige Wut, aufgrund der herrschenden Machtverhältnisse in Europa und aus Rücksicht auf die eigenen Minderheiten in Polen selbst innerhalb der eigenen Staatsgrenzen nicht mehr so uneingeschränkt gegen die Polen vorgehen zu können wie vor dem Kriege. Für sich genommen machte es wenig Sinn, Ideologie und Verwaltungspraxis, die vor dem Kriege gegenüber einer Millionen zählenden polnischen Teilgesellschaft in Anschlag gebracht worden waren, nunmehr auf die ca. eine Million zählende polnische Restminderheit zu übertragen. Doch das Trauma der amputierten Ostgebiete und der „blutenden Grenze“ saB offensichtlich so tief, daB ein Rückgriff auf die erprobten Vorkriegsmethoden der Polenbekämpfung unverzichtbar erschien.

Mit der Niederhaltung der polnischen Grenzminderheiten sollte dem Nachbarstaat Polen jede Möglichkeit eines direkten Zugriffes oder einklagbaren Anspruches auf sein ethnisches Vorfeld genommen werden. Dabei wurden dem nationalen Gegner Absichten unterstellt, die für die eigene Schutzpolitik gegenüber den deutschen Bevölkerungsteilen jenseits der deutsch-polnischen Grenze genauso und in noch viel größeren AusmaB bestimmend gewesen sind. Dessen ungeachtet wird man kaum bezweifeln können, daB es in bezug auf die deutsche Ostgrenze einen massiven und kontinuierlichen Bedrohungskomplex gegeben hat, der von großen Teilen der Öffentlichkeit und von den verantwortlichen Regierungen gleichermaßen geteilt worden ist. In diesem Zusammenhang ist es eher von zweitrangiger Bedeutung, inwieweit diese Ängste berechtigt oder nur eingebildet, ob sie spontan oder manipuliert gewesen sind. Sie waren vorhanden und haben nachhaltig auf die Stellung und Behandlung der polnischen Grenzminderheiten zurückgewirkt.

Diese Polen - nicht die polnischen Erwerbsimmigranten im Ruhrgebiet - galten schlechterdings als potentielle Agenten des angrenzenden Nachbarstaates, als mögliche Steigbügelhalter weiterer polnischer Expansionsbestrebungen oder - weniger dramatisch - als generelle Unruhe- und Unsicherheitsfaktoren an den problematischsten Abschnitten der deutschen Staatsgrenzen. Viele der hier vorgelegten Dokumente sind von eben diesem Verdacht geprägt. Alle Verbindungen, die von seiten der polnischen Grenzminderheiten nach Polen unterhalten wurden, sind darum peinlichst genau registriert worden, angefangen vom kleinen Grenzverkehr über individuelle Polenaufenthalte polnischer Minderheitenvertreter, Jugend- und Gruppenfahrten, Ferienlager, Fortbildungskurse oder Wallfahrten nach Tschenstochau u. ä. m. Umgekehrt ist die Anwesenheit von Persönlichkeiten aus Polen oder von polnischen Konsularangehörigen bei Veranstaltungen der polnischen Grenzminderheiten mit großem Mißtrauen beobachtet worden. Auch Lehrer an polnischen Minderheitenschulen, die einen polnischen $\mathrm{PaB}$ hatten, wurden

26 Staatsarchiv Potsdam, Pr. Br. Rep. 2A, Nr. 1319 - Rundschreiben des PreuBischen Ministers des Innern an die Regierungspräsidenten der Grenzgebiete betr.: Berichterstattung in Angelegenheiten der polnischen Minderheiten und der nationalpolnischen Bewegung. - Berlin, den 27. Dezember 1932. 
ständig observiert. Im Zuge der Überwachungen aller möglichen ideellen, kulturellen und personellen Querverbindungen und Einflüsse stellten die zuständigen Aufsichtsbehörden immer wieder Spekulationen über das Ausmaß finanzieller Unterstützung an, die von seiten des polnischen Staates an die polnische Grenzminderheit in Deutschland geflossen sein könnte. Die kostenlose Abgabe von Büchern, Kleidungsstücken, kleineren Gebrauchsgegenständen bei feierlichen Anlässen oder Lebensmittel standen beispielsweise regelmäßig unter Verdacht, von jenseits der Grenze bezahlt worden zu sein. Überwachung war überhaupt das zentrales Anliegen und eine Grundmaxime preußischer Polenpolitik in den Grenzgebieten.

Schon bald nach Kriegsende wurde mit dem Aufbau bzw. der Rekonstruktion eines Polizeispitzelsystems in den deutsch-polnisch gemischten Grenzgebieten begonnen und die Observierung polnischer Vereine und Zusammenkünfte eingeleitet. Die regionalen Aufsichtsbehörden sind von Berlin aus seit 1922 wiederholt zu einer strengen Überwachung der polnischen Grenzminderheit angehalten worden, so beispielsweise durch einen ausführlichen Erlaß des preußischen Innenministeriums vom 27. Dezember 1932, worin zu einer „schärferen Beobachtung“ der polnischen „Wühlarbeit“ im Grenzgebiet aufgerufen wurde. Presse-, Vereins- und Versammlungswesen, Kirche und Schule wurden als besonders zu beachtende Aktionsfelder der ,polnischen Agitation " nahegelegt. ${ }^{27}$ Von Interesse waren aber auch „Vorkommnisse, die sich im Alltagsleben, besonders in den gemischtsprachigen Grenzgebieten ereignen, so z.B. Grenzzwischenfälle, Überfälle, Angriffe wörtlicher und tätlicher Art auf Angehörige der Minderheit, Wirtshausstreitigkeiten mit Minderheitsangehörigen ..." Berichtspflichtig waren alle Dienststellen vom einfachen Dorfpolizisten (Landjäger) aufwärts bis zum Oberpräsidenten der betreffenden Provinz. In der Praxis sah das häufig so aus, daß ein übersetzter Zeitungsartikel aus der polnischen Minderheitenpresse im preußischen Innenministerium zum Anlaß genommen wurde, von der zuständigen nachgeordneten Behörde eine Stellungnahme und Hintergrundinformationen zu einem bestimmten Vorfall einzufordern.

Auffallendes Charakteristikum der deutschen amtlichen Minderheitenbeobachtung und zugleich wichtigstes Unterscheidungsmerkmal zu den parallelen polnischen Quellen war der generelle Vorrang von Ereignismeldungen vor einer flächendeckenden schematischen Berichterstattung. 1937 hatte der Oberpräsident von Breslau an alle Landräte, Oberbürgermeister und Polizeidienststellen in diesem Sinne nachdrücklich gefordert, entsprechende Lageberichte sollten in erster Linie die „Aufführung zahlreicher beweiskräftiger Einzelheiten" sicherstellen. ${ }^{28}$ Bei solchen Vorgaben ist es nicht verwunderlich, daß selbst in den zusammenfassenden Berichten der Landräte an die Oberpräsidenten und in deren Rapports an den preußischen Innenminister immer noch sehr plastische, aussagekräftige Informationen zur jeweiligen Situation und Stimmung in den Grenzgebieten zu finden sind. Periodische Lageberichte bildeten zur Zeit der Weimarer Republik eher die Ausnahme. Sie sind mit einer gewissen Regelmäßigkeit nur in akuten Krisenzeiten abgefaßt worden, so beispielsweise für Ostpreußen zur Zeit des polnischrussischen Krieges. Für die Provinz Grenzmark Posen-Westpreußen stoßen wir seit Mitte der zwanziger Jahre auf zusammenfassende Jahresberichte und seit Ende der zwanziger

27 Nach Schulz, S. 277-282.

28 Archiwum Państwowe Wroclaw, Rejencja Opolska Nr. 1/1926 - Der Oberpräsident in Breslau an die Landräte, Oberbürgermeister usw. betr.: Lageberichte über die polnische Minderheit - Breslau, den 14.3.1937. (Aktenstück Nr. 303 der vorliegenden Dokumentation). 
Jahre im oberschlesischen Industrierevier auch schon auf formalisierte periodische Berichte der Polizeipräsidenten. Doch erst die totalen reichsweiten Überwachungspraktiken der Nationalsozialisten brachten auch für die Grenzgebiete seit 1934 die Verpflichtung zu einer systematischen Berichterstattung, wobei aber nur in Oberschlesien gesonderte Minderheitenlageberichte erstellt worden sind.

Was die Grenzpolizeiposten, Landjäger und Landräte im einzelnen an Beobachtungen und Bewertungen vorzubringen hatten, war in der Regel nicht übermäßig aufregend, zumindest nicht im Sinne ständiger nationalpolitischer Konflikte oder irredentistischer Umtriebe, auch wenn es in der Natur der Sache lag, daß ihre V-Männer bemüht waren, mit möglichst zugkräftigen Nachrichten über die polnische Gefahr dies- und jenseits der Reichsgrenze aufzuwarten, um sich unentbehrlich zu machen. Es war gar nicht so einfach, die Staatsgefährlichkeit der hauptsächlich mit nackten Existenzsorgen beschäftigten polnischen Grenzminderheit nachzuweisen, hatten die Aufsichtsbehörden doch sogar Schwierigkeiten, ihre Gegner national genau zu fixieren, die irgendwo unter den ,heimlichen Polen“, „schwankenden Elementen“ und den „fanatischen Polen“ zu suchen waren. Selbst dort, wo die „fanatischen Polen“, die „radikalen Polenanhänger“ und „polnischen Agitatoren" vermutet worden sind, waren keine wirklich gefährlichen Widersacher des deutschen bzw. preuBischen Staates auszumachen. Es waren überwiegend kleine Leute, die irgendwelche Funktionen und Ämter in polnischen Organisationen übernommen hatten. Ihr berufliches Spektrum (Organist, Drogist, Friseur, Rangierer, Maurer, Stellmacher, Windmüller u. ä. m.) spiegelte noch einmal die flache Sozialpyramide in diesen polnisch besiedelten Randzonen. Ihr Dienst an der "polnischen Sache“ bedeutete vielfach nicht mehr, als daB sie beispielsweise bei bevorstehenden Wahlen in Wirtshäusern entsprechend Stimmung machten oder von Haus zu Haus zogen, um polnische Familien zur Treue für ihr Volkstum zu ermahnen, d. h. konkret, sie vor dem eventuell bevorstehenden Verkauf ihres Hauses oder Grundstückes an Deutsche abzuhalten, um Unterstützung polnischer Vereinigungen zu werben und zum Besuch der Kinder in polnischen Minderheitenschulen zu ermuntern. Daß bei solchen Gelegenheiten manchmal großspurige und glühende nationalpolnische Bekenntnisse abgegeben worden sind - wie z. B. „cześć do Odry“ (Heil bis zur Oder) -, gehörte gleichsam zum Geschäft, blieb aber in der Regel ohne nachhaltige Folgen.

Ernster waren die polnischen Geistlichen und Lehrer zu nehmen, die von Berufs wegen einflußreiche Multiplikatoren gewesen sind und auch außerhalb ihres eigentlichen Tätigkeitsbereiches polnisch-patriotische Gesinnungsarbeit geleistet haben. Polnische katholische Priester, die von der Kanzel aus ihre Landsleute vor dem Verkauf ihrer Grundstücke an Deutsche warnten und auswanderungswilligen Optanten die Ausstellung der für die Repatriierung notwendigen Bescheinigungen verweigerten, stellten in Anbetracht ihrer traditionell hochstehenden Autorität bei der polnischen Grenzbevölkerung einen nicht zu unterschätzenden Faktor nationalpolnischen Lebens dar. Ähnliches galt für die häufig aus Polen kommenden Lehrer in polnischen Minderheitenschulen mit ihrem außerschulischen Engagement in diversen polnischen kulturellen Organisationen. Doch auch von diesen Kreisen ist in der Regel der deutsche bzw. preußische Staat als vorgegebener und nicht in Frage gestellter Rahmen ihrer Aktivitäten respektiert worden.

Es war schon erstaunlich, welche Sachverhalte den berichterstattenden regionalen Grenzbehörden ausgereicht haben, um die ,polnische Gefahr“ an der deutsch-polnischen Grenze den vorgeordneten Dienststellen glaubhaft zu machen. So sind beispielsweise bescheidene Weihnachtsbescherungen für Kinder, die die polnische Minderheitenschule 
besucht haben, einer peniblen Inventur unterzogen worden. Tassen, Schürzen u. ä. m. mußten als Beweisstücke für die „polnische Wühlarbeit“ unter der Grenzbevölkerung herhalten. Besonders auffällig war die aus heutiger Sicht kaum nachvollziehbare Empfindlichkeit gegenüber polnischen Nationalsymbolen. So konnte es ernsthafte Konsequenzen haben, ob eine Fahne mit den polnischen Nationalfarben bei einem Umzug auf- oder ausgerollt mit sich geführt wurde. Es reichten aber schon kleinere Embleme, silberne polnische Abzeichen mit dem polnischen Adler, rot-weiße Schleifen oder $\mathrm{Pa}$ pierfähnchen bei Beerdigungen oder Fronleichnamfesten, um die anwesenden Polizeibeamten zum Einschreiten zu veranlassen. Man kann sich die geradezu hysterisch anmutende Empfindlichkeit gegenüber dieser Art polnischer Selbstdarstellung nur aus dem Bestreben erklären, mit rigiden Verboten solcher Zeichen, die ja zugleich Symbole des polnischen Nachbarstaates gewesen sind, nicht die geringsten Zweifel an den Hoheitsrechten im Grenzgebiet aufkommen zu lassen.

Die Kleinlichkeit der örtlichen und regionalen Berichterstattung, so kann man resümierend feststellen, rührte zu einem erheblichen Teil aus der Beengtheit und relativen Ereignislosigkeit der berichtspflichtigen Zuständigkeitsbereiche und dem Bestreben der Beamten, ihrem Auftrag nach Überwachung der polnischen Grenzminderheit gewissenhaft nachzukommen. Bei dieser Konstellation muBte einfach alles zusammengetragen werden, was auch nur im entferntesten beweiskräftig zu sein schien. Es waren darum meist nur kleine Vorfälle, die von den Beamten in teilweise sehr schlechtem Deutsch zu Papier gebracht werden konnten und selbst in ausgesprochenen Krisenzeiten der deutsch-polnischen Beziehungen, wie sie für den Beginn und die letzten Jahre des hier gewählten Beobachtungszeitraums charakteristisch gewesen sind, ist es letztlich nur zu einer Häufung solcher Vorkommnisse gekommen, wie den hier veröffentlichten Aktenstücken leicht zu entnehmen ist. Diesem unleugbaren Tatbestand stand der mit Nachdruck von den vorgeordneten Dienststellen wiederholte Auftrag an die regionalen und lokalen Behörden, die ,polnische Gefahr" in ihren jeweiligen Zuständigkeitsbereichen einer ständigen Observation zu unterziehen.

Die makropolitischen Bestimmungsfaktoren dieses Auftrages sind bereits besprochen worden; an diese knüpften sich freilich Motivationshintergründe, die aus den spezifischen Bedürfnislagen der Grenzregionen selber herrührten, bzw. aus der regionalpolitischen Interessenvertretung der dortigen Verwaltungsbehörden. Mit einer möglichst drastischen Ausmalung der ,polnischen Gefahr" in der amtlichen Berichterstattung konnten Defizite in den jeweiligen Zuständigkeitsbereichen übertüncht bzw. entschuldigt werden. Außerdem dienten entsprechende Brandmeldungen nach Berlin nur allzu häufig und allzu durchsichtig der Jagd nach dringend benötigten staatlichen Subventionen für den Ausbau der generell strukturschwachen Grenzgebiete. Der durchweg nüchterne Berichtston der an der Ostgrenze des Reiches stationierten und regionalpolitisch nicht im selben Maße engagierten militärischen Dienststellen kann als zusätzliche Bestätigung dieser Beobachtung dienen. Die ,polnische Gefahr" stellte in dieser Hinsicht nur eine ideologische Metapher für die Darstellung allgemeiner Problemlagen dieser Grenzgebiete dar und der permanente Hinweis auf "polnische Umtriebe“ von seiten der örtlichen und regionalen Staatsorgane erweist sich dergestalt als ein argumentatives Vehikel zur Beseitigung derselben. ${ }^{29}$

29 Das war übrigens keine Besonderheit des deutsch-polnischen Grenzabschnittes. Siehe dazu vergleichsweise Jaworski, Rudolf: Grenzlage, Rückständigkeit und nationale Agitation: Die „Bayerische Ostmark“ in der Weimarer Republik. In: Zeitschrift für bayerische Landesgeschichte 41 (1978) H. 1. S. 256 ff. 
Der nationalsozialistische Umbruch in Deutschland brachte wider Erwarten keine Zuspitzung der deutsch-polnischen Konflikte, weder auf der zwischenstaatlichen Ebene noch in bezug auf die Minderheitenfrage: Ganz im Gegenteil kam es zu einer merklichen Klimaverbesserung. ${ }^{30}$ Das hatte vor allem damit etwas zu tun, daß in der nationalsozialistischen Ideologie prinzipiell kein Platz für kleinräumig ausgetragene Volkstums- und Grenzkämpfe vorgesehen war. Die absolut gesetzten Kategorien von Raum und Rasse veranlaßten die Nationalsozialisten sogar, über einen „großzügigen Ausgleich“ mit dem polnischen Nachbarn „,von Volk zu Volk“ nachzudenken. In diesem Sinne hatte sich Adolf Hitler bereits in seiner berühmten Reichstagsrede vom 17. Mai 1933 gegen Assimilierungsbestrebungen jeglicher Art ausgesprochen, auch solchen von deutscher Seite: „Wir kennen daher auch nicht den Begriff des Germanisierens. Die geistige Mentalität des vergangenen Jahrhunderts, aus der man glaubte, vielleicht aus Polen und Franzosen Deutsche machen zu können, ist uns genauso fremd, wie wir uns leidenschaftlich gegen jeden umgekehrten Versuch wenden. Wir sehen die europäischen Nationen um uns als gegebene Tatsache. Franzosen, Polen usw. sind unsere Nachbarvölker und wir wissen, daß kein geschichtlich denkbarer Vorgang diese Wirklichkeit ändern könnte.“31

Solche und ähnliche Äußerungen ließen die Repräsentanten der polnischen Minderheit in Deutschland verständlicherweise neuen Mut schöpfen, daß fortan der Entnationalisierungsdruck auf ihre Landsleute nachlassen oder gänzlich aufhören würde. In den Grenzgebieten wurden diese Sätze des Führers wie eine Heilsbotschaft und wie ein Schutzschild immer wieder zitiert. Für die örtichen Behörden waren diese ständigen Berufungen auf die höchste Autorität des Reiches äuBerst unangenehm, hatte sich doch an ihrem Auftrag zu einer kontinuierlichen und strengen Überwachung der polnischen Minderheit grundsätzlich nichts geändert. Außerdem mußten sie zur Zeit der nationalsozialistischen Machtergreifung Übergriffe von SA-Formationen auf Angehörige und Einrichtungen der polnischen Minderheit im Grenzgebiet zügeln. Diese hörten erst nach AbschluB der deutsch-polnischen Nichtangriffserklärung im Jahre 1934 auf, als alle antipolnischen Feindseligkeiten zentral unterbunden worden sind.

Nun ist die unleugbare Entspannung, welche die nationalsozialistische Herrschaft für die in Deutschland lebenden Polen mit sich gebracht hatte, keinesfalls ein Selbstzweck gewesen und war außerdem unterschwellig von zahlreichen gegenläufigen Tendenzen begleitet. Die schon zur Weimarer Zeit charakteristische Neigung, die Polenpolitik im eigenen Staat reaktiv an das jeweils aktuelle Verhältnis zur Republik Polen und ihrer Minderheitenpolitik zu binden, ist von den Nationalsozialisten insofern systematisiert worden, als sie eine strikte Unterordnung der Minderheiten- unter die Außenpolitik vorgenommen haben. Die polnischen Grenzminderheiten verloren damit endgültig den Anspruch, als eigenständiger Faktor wahrgenommen und behandelt zu werden, sie waren fortan ausschließlich Verhandlungsmasse der deutschen Außen- und Polenpolitik.

Langfristiges Ziel - und auch hierin handelte es sich lediglich um eine Radikalisierung der Konzeptionen aus den vorausgegangenen Jahrzehnten - war eine Isolierung

30 Dazu u.a. Broszat: Zweihundert Jahre, S. 234 ff.; Wojciechowski, Marian: Stosunki polsko-niemieckie 1933-1938. Poznań 1980, S. 33 ff.

31 Zitiert nach Domarus, Max: Hitler. Reden und Proklamationen. Bd. 1: 1932-1938. Würzburg 1962, S. 273. 
und Liquidierung der polnischen Grenzminderheiten. ${ }^{32}$ Der von den Nationalsozialisten eingeleitete Wandel in der deutschen Polenpolitik war demnach längst nicht so radikal, wie er sich äußerlich zu geben bemüht gewesen ist. Der plötzliche und verordnete Umschwung in der öffentlichen Einstellung zur Polenfrage konnte nicht darüber hinwegtäuschen, daß er rein taktischer Natur gewesen ist und eigentlich nicht mehr war als eine vorläufige, nach außen hin demonstrierte klimatische Verbesserung, nicht aber eine grundsätzliche Abkehr von polenfeindlichen Traditionen. In der praktischen Minderheitenpolitik waren die apodiktisch formulierten Lehrsätze der Nationalsozialisten von der sauberen Trennung der Rassen in den ethnisch gemischten Grenzgebieten ohnehin nicht anzuwenden. Da andererseits hochoffiziell jeglichen Assimilationsbestrebungen abgeschworen worden war, behalf man sich mit dem begrifflichen Kunstgriff der „Wiedereindeutschung“ der östlichen Grenzgebiete.

Aktive Germanisierungspolitik wurde dergestalt als Rückgängigmachung von Assimilierungsvorgängen $\mathrm{zu}$ rechtfertigen versucht, die in der Vergangenheit fälschlicherund ungerechtfertigterweise in Richtung auf das Polentum stattgefunden hätten. Um diese Ziele offensiver und rücksichtsloser durchsetzen zu können, ist von den Nationalsozialisten ein spezieller Kampfverband, der „Bund Deutscher Osten“ geschaffen worden, der in aggressiver Weise eine Verdrängung der Polen propagiert hat ${ }^{33}$ In vieler Hinsicht sind die alten Auseinandersetzungen z. B. um das polnische Minderheitenschulwesen fortgesetzt worden, nur die Methoden der Behinderung und Überwachung hatten sich in Form verschärfter, wenn auch teilweise weiterhin indirekter und verdeckter Schikanen geändert. Neue Reibungspunkte waren hinzugekommen, wie z.B. der unaufgelöste Widerspruch zwischen den einheitlichen Staatsjugendorganisationen der HJ und des BDM auf der einen und den fortbestehenden polnischen Jugendorganisationen auf der anderen Seite. Unüberbrückbar erwies sich außerdem die Kluft zwischen der nationalsozialistischen Weltanschauung und dem Katholizismus, der gerade im Polentum besonders tief verankert gewesen ist. Entsprechende Verfolgungen führten sogar zu einer merklichen Annäherung der gleichermaßen in Bedrängnis geratenen deutschen und polnischen Katholiken, was insofern bemerkenswert ist, als die Germanisierungspolitik zur Zeit der Weimarer Republik innerhalb der deutschen katholischen Kirchenführung noch durchaus auf Zustimmung gestoßen war.

Die in Deutschland lebenden Polen sollten in ihren eigenen Organisationen eingesperrt, identifizierbar und manövrierunfähig gemacht werden. Hierzu diente beispielsweise die Anordnung, das Recht auf Teilnahme an polnischen Veranstaltungen von der Mitgliedschaft im Bund der Polen abhängig zu machen. Wie zur Weimarer Zeit umging die nationalsozialistische Gesetzgebung das Problem der nationalen Minderheiten insofern, als daß diskriminierende Bestimmungen nicht explizit auf fremdnationale Bevölkerungsanteile bezogen worden sind. Das galt beispielsweise für das 1937 vom Reichsinnenminsterium erlassene „Gesetz über den Schutz der Reichsgrenze und über Vergeltungsmaßnahmen", wonach Minderheitenangehörige aus ihren Beschäftigungsverhältnissen entlassen, im freien Gebrauch ihres Besitzes eingeschränkt oder sogar

32 Und zu den folgenden Abschnitten Wrzesinski: Ruch polski, S. 247 ff.: ders.: Die Politik der nationalsozialistischen Machthaber gegenüber der polnischen Minderheit in Deutschland (1933-1945). In: W. Jacobmeyer (Hg.): Deutschland und Polen von der nationalsozialistischen Machtergreifung bis zum Ende des Zweiten Weltkrieges. Braunschweig 1986, S. 85-92.

33 Fiedor, Karol: Bund Deutscher Osten. Zwiazek Niemieckiego Wschodu w systemie antypolskiej propagandy. Warszawa 1977. 
aus dem Grenzgebiet ausgesiedelt werden konnten. ${ }^{34}$ Mit derartigen Blankovollmachten wurden die polnischen Grenzminderheiten ungeschützt der Willkür örtlicher Verwaltungsorgane ausgesetzt.

Die im selben Jahr am 5. November 1937 von Deutschland und Polen veröffentlichte Minderheitenerklärung änderte an dieser Situation überhaupt nichts. ${ }^{35}$ Seit Herbst 1938 verstärkte sich vielmehr der Druck auf die polnische Minderheit in Form gehäufter individueller Übergriffe örtlicher Parteizellen auf polnische Lokale, Wohnungen polnischer Minderheitenführer, Schulen und Versammlungen. Doch es blieb nicht nur bei diesen spontanen, in Wirklichkeit zentral gelenkten Terrorakten. Die Polizeiorgane konfiszierten Mitgliederlisten polnischer Organisationen, es wurden Proskriptionsverzeichnisse für die endgültige Abrechnung mit den als unverbesserlich eingestuften Polen angelegt. Polnische Aufschriften sind von öffentlichen Plätzen entfernt, der öffentliche Gebrauch der polnischen Sprache eingeschränkt und die Germanisierung von Orts- und Familiennamen vorangetrieben worden. Polnische Bibliotheken muBten geschlossen werden. Traurige Höhepunkte erreichten diese Verfolgungsjagden in den Monaten und Wochen vor dem Kriegsausbruch, wobei parallele Repressionen gegen Deutsche in Polen von der NS-Propaganda für die Öffentlichkeit zu einer scheinbaren Spirale von Aktion und Reaktion präpariert worden sind. Auf diese Weise wurde an der deutsch-polnischen Grenze eine Atmosphäre höchster Alarmbereitschaft und unversöhnlicher Feindseligkeit erzeugt und das Minderheitenproblem auf einmal wieder zum Angelpunkt der deutschpolnischen Beziehungen erhoben. Am 4. September 1939 wurde der Polenbund aufgelöst und sein Vermögen konfisziert.

So unaufrichtig die Abwendung der Nationalsozialisten von den antipolnischen Positionen der Weimarer Zeit gewesen ist, so unglaubwürdig war andererseits das manipulierte Hochspielen der Minderheiten- und Grenzfrage vor dem Ausbruch des Zweiten Weltkrieges. Für die Polen in den Grenzgebieten ging damit die wohl widersprüchlichste Ära ihres Minderheitendaseins zu Ende, wobei sie zuletzt in der wenig beneidenswerten Situation gewesen sind, als erste Polen mit Praktiken der NS-Herrschaft konfrontiert zu werden, wie sie nach dem 1. September 1939 auch für ihre Landsleute jenseits der nicht mehr existenten deutsch-polnischen Grenze in noch viel ungehemmterer Weise wirksam werden sollten.

34 Erste Durchführungsverordnung zum Gesetz über die Sicherung der Reichsgrenze und über Vergeltungsmaßnahmen vom 17. August 1937. In: Reichsgesetzblatt Teil 1. Nr. 95 vom 20. August 1937.

35 Deutsch-polnische Minderheitenerklärung: In: Nation und Staat 11 (1937/38), S. 151 f. Chalupczak. Henryk: Deklaracja z 5 listopada 1937r. a problem mniejszości w Niemczech. In Przegląd Zachodni LV (1989) Nr. 1, S. 109-128. 
